\title{
Predictors of modern contraceptive use among adolescent girls and young women in sub-Saharan Africa: a mixed effects multilevel analysis of data from 29 demographic and health surveys
}

\author{
Bright Opoku Ahinkorahio
}

\begin{abstract}
Background: The use of modern contraceptives among adolescent girls and young women (AGYW) in subSaharan Africa (SSA) remains an issue that needs urgent attention. This present study assesses the individual and contextual factors associated with modern contraceptive use among AGYW in SSA.

Methods: Data for this study was obtained from the latest Demographic and Health Surveys (DHS) conducted between January 2010 and December 2018 across 29 countries in SSA. Data were analysed with Stata version 14.2 by employing both Pearson's chi-square test of independence and a multilevel binary logistic regression. The selection of variables for the multilevel models was based on their statistical significance at the chi-square test at a $p<0.05$. Model fitness for the multilevel models was checked using the log likelihood ratios and Akaike's Information Criterion (AIC) and the results were presented using adjusted odds ratios (aOR) at 95\% confidence interval (Cl).

Results: It was found that $24.7 \%$ of AGYW in SSA use modern contraceptives. In terms of the individual level factors, the study showed that AGYW aged 15-19 [aOR $=0.86, \mathrm{Cl}=0.83-0.90]$, those who were married [aOR $=0.83, \mathrm{Cl}=0.79-0.87]$, Muslims $[\mathrm{aOR}=0.59, \mathrm{Cl}=0.57-0.62]$, working $[\mathrm{aOR}=0.92, \mathrm{Cl}=0.89-0.95]$, those who had no child [aOR $=0.44, \mathrm{Cl}=0.42-$ 0.47], those who had no exposure to newspaper/magazine $[\mathrm{aOR}=0.44, \mathrm{Cl}=0.63-0.71]$ and radio $[\mathrm{aOR}=0.82, \mathrm{Cl}=0.78-$ 0.86] had lower odds of using modern contraceptives. Conversely, the use of modern contraceptives was high among AGYW whose age at first sex was 15-19years [aOR $=1.20, \mathrm{Cl}=1.12-1.28]$. With the contextual factors, the odds of using modern contraceptives was low among AGYW who lived in rural areas [aOR $=0.89, \mathrm{Cl}=0.85-0.93$ ] and in communities with low literacy level [aOR $=0.73, \mathrm{Cl}=0.70-0.77$ ] and low socio-economic status [aOR $=0.69, \mathrm{Cl}=0.65-0.73]$.

Conclusion: Several individual and contextual factors are associated with modern contraceptive use among AGM in SSA. Therefore, Governments in the various countries considered in this study should intensify mass education on the use of modern contraceptives. This education should be more centered on AGYW who are in socio-economically disadvantaged communities, those who are not married, Muslims, those with high parity and high fertility preferences and those who are working.
\end{abstract}

Keywords: Utilization of modern contraceptives, Adolescent girls, Young women, Sub-Saharan Africa, Reproductive health

Correspondence: brightahinkorah@gmail.com

School of Public Health, Faculty of Health, University of Technology Sydney,

Sydney, Australia

C C The Author(s). 2020 Open Access This article is licensed under a Creative Commons Attribution 4.0 International License, which permits use, sharing, adaptation, distribution and reproduction in any medium or format, as long as you give appropriate credit to the original author(s) and the source, provide a link to the Creative Commons licence, and indicate if changes were made. The images or other third party material in this article are included in the article's Creative Commons licence, unless indicated otherwise in a credit line to the material. If material is not included in the article's Creative Commons licence and your intended use is not permitted by statutory regulation or exceeds the permitted use, you will need to obtain permission directly from the copyright holder. To view a copy of this licence, visit http://creativecommons.org/licenses/by/4.0/. The Creative Commons Public Domain Dedication waiver (http://creativecommons.org/publicdomain/zero/1.0/) applies to the data made available in this article, unless otherwise stated in a credit line to the data. 


\section{Background}

The sexual and reproductive health (SRH) of adolescent girls and young women (AGYW) aged 15-24 forms a key component of the global burden of sexual ill health [1]. This is because neglecting SRH of AGYW has detrimental effect on their transition to adulthood [2]. The SRH of AGYW has become critical because it has been estimated that 16 million girls aged 15-19 give birth each year, and this constitutes about $11 \%$ of all births worldwide and $95 \%$ of these births occur in low-and middle-income countries (LMICs), including subSaharan Africa (SSA) [3]. Other studies have indicated that most of these births result from unintended pregnancies and in SSA, $44 \%$ of these unintended pregnancies occur among AGYW [4, 5]. This unquestionably accounts for the high unsafe abortion rates among AGYW in SSA [6]. Apart from these SRH challenges, AGYW in SSA also face risk of exposure to HIV and other sexually transmitted infections (STIs) [1].

As part of efforts to deal with the SRH challenges of AGYW, the United Nations in 2015 developed the Sustainable Development Goals and Goal 3.7 focuses on ensuring universal access to sexual and reproductive health-care services, including family planning, information and education, and the integration of reproductive health into national strategies and programmes by 2030 [7]. The achievement of this Goal, especially for AGYW who often go through a lot of SRH challenges depends on the access, consistent and effective use of modern contraceptives $[8,9]$.

However, studies have indicated that the use of modern contraceptives among AGYW in SSA remains an issue that needs urgent attention [10-12]. Globally, it is estimated that over 220 million women in LMICs have an unmet need for contraception [13]. Although the prevalence of unmet need for contraception among AGYW in SSA is unknown, approximately $25 \%$ of women in the subregion (i.e. about 47 million) have unmet need for contraception [14], with a majority of them being AGYW [15-17].

Theoretically, the use of modern contraceptives among AGYW can be understood within the theoretical underpinning of the Health Belief Model which provides explanations to the likelihood of using modern contraceptives among AGYW from the point of perceived risks [18]. In this regard, AGYW who consider themselves as being at risk of unintended pregnancies and STIs may be more likely to use modern contraceptives compared to those who consider themselves not to be at risk. In the absence of risk perception, studies have shown that despite the desire of AGYW to use contraceptives, a majority of them have challenges with access to contraceptive services [15-17]. These challenges can be understood within the context of Anderson and Newmans' Health Care Utilisation Model which proposes that the use of a service, which includes modern contraceptives is influenced by predisposing factors such as demographics, health beliefs and social structures; enabling factors which include the availability of health personnel and facilities, waiting time and health insurance subscription and need for care factors which focuses on factors which are people's perception and evaluation of their health that serve as motivation to use a service [19].

Based on these theoretical underpinnings, it can be affirmedthat individual and contextual factors play a key role in the use of modern contraceptives among AGYW. However, studies on modern contraceptives use among AGYW in SSA have often focused on individual level factors such as age, marital status, religion, ethnicity, level of education, wealth status and occupation [17, 20-23]. Apart from their focus on individual level factors, most of these studies examined the predictors of contraceptive use (which includes traditional methods) instead of looking at modern contraceptives which have been considered the most effective of all contraceptive methods [24-26]. Again, studies on predictors of contraceptives among AGYW in SSA have been done in specific countries like Congo [20], Ghana [23] Malawi [21], South Africa [17] and Tanzania [22]. Although a recent study explored the predictors of modern contraceptive use among young women in LMICs, which included countries in SSA, the major focus of the authors was on community level factors that influence modern contraceptive use [27]. One of the gaps in this study which the current study seeks to fill is the lack of understanding of the interaction between individual and contextual-level factors in influencing the use of modern contraceptives of among AGYW. Again, Mutumba, Wekesa [27] used data from the 2008 to 2016 Demographic and Health Surveys (DHS). However, the current study considers current DHS data from 2010 and 2018 since variations in contraceptive accessibility and usage may have happened in the last few years. Using a multilevel modelling approach, this present study assesses the individual and contextual factors associated with modern contraceptive use among AGYW in SSA. Findings from this study will help to formulate useful interventions and strategies in addressing the use of modern contraceptive among AGYW in the sub-region.

\section{Methods}

\section{Data source}

Data for this study was obtained from the latest DHS conducted between January 2010 and December 2018 across 29 countries in SSA. The survey was designed to collect and provide data on various demographic indicators such as contraceptive use [28]. The details of the methodology employed in the DHS are documented by Corsi, Neuman [29]. In this study, only AGYW (15-24 years) who had ever had sex and had information on the use of contraceptives were considered $(n=91,083)$. 
Table 1 Detailed description of the countries, survey years and the sample used in this study

\begin{tabular}{|c|c|c|c|c|}
\hline Country & Survey year & Adolescent girls and young women & Sample (N) & Sample (\%) \\
\hline 1. Angola & $2015-16$ & 6423 & 4822 & 5.3 \\
\hline 2. Benin & 2017-18 & 6251 & 4084 & 4.5 \\
\hline 3. Burkina Faso & 2010 & 6592 & 4319 & 4.7 \\
\hline 4. Burundi & $2016-17$ & 7218 & 2579 & 2.8 \\
\hline 5. Cameroon & 2011 & 6708 & 4187 & 4.6 \\
\hline 6. Chad & 2014-15 & 6884 & 3374 & 3.7 \\
\hline 7. Comoros & 2012 & 2282 & 683 & 0.8 \\
\hline 8. Congo & $2011-12$ & 3963 & 3235 & 3.6 \\
\hline 9. Côte d'Ivoire & $2011-12$ & 3984 & 2814 & 3.1 \\
\hline 10. DR Congo & 2013-14 & 7661 & 4953 & 5.4 \\
\hline 11. Ethiopia & 2016 & 6401 & 2625 & 2.9 \\
\hline 12. Gabon & 2012 & 3407 & 2487 & 2.7 \\
\hline 13. Gambia & 2013 & 4564 & 1875 & 2.1 \\
\hline 14. Ghana & 2014 & 3327 & 2046 & 2.3 \\
\hline 15. Guinea & 2018 & 4267 & 2315 & 2.5 \\
\hline 16. Kenya & 2014 & 11,483 & 3215 & 3.5 \\
\hline 17. Lesotho & 2014 & 2842 & 589 & 0.7 \\
\hline 18. Liberia & 2013 & 3499 & 2921 & 3.2 \\
\hline 19. Malawi & 2015-16 & 10,369 & 7382 & 8.1 \\
\hline 20. Mali & 2018 & 4116 & 2649 & 2.9 \\
\hline 21. Namibia & 2013 & 3577 & 2151 & 2.4 \\
\hline 22. Nigeria & 2018 & 15,267 & 4740 & 5.2 \\
\hline 23. Rwanda & 2014-15 & 5252 & 2084 & 2.3 \\
\hline 24. Senegal & 2010-11 & 6773 & 2433 & 2.7 \\
\hline 25. Sierra Leone & 2013 & 6739 & 3059 & 3.4 \\
\hline 26. Togo & 2013-14 & 3337 & 2188 & 2.4 \\
\hline 27. Uganda & 2016 & 8058 & 5303 & 5.8 \\
\hline 28. Zambia & 2018 & 5799 & 3832 & 4.2 \\
\hline 29. Zimbabwe & 2015 & 3938 & 2138 & 2.4 \\
\hline
\end{tabular}

Table 1 gives detailed description of the countries, survey years and the sample used in this study. The datasets for the DHS are available at http://dhsprogram.com/ data/available-datasets.cfm.

\section{Definition of variables}

\section{Outcome variable}

The outcome variable for the study was 'current modern contraceptive usage'. It was derived from the question, "Are you currently using any type of contraceptive"? Responses to this question were coded as "no method", "folkloric method", "traditional method" and "modern method". Details of the specific contraceptives under each of the methods have been described elsewhere [30]. The existing DHS variable excluded women who were pregnant and those who had never had sex. For the purpose of this study, AGYWwho were using modern methods were coded as ' 1 ' whiles those who were not using any methods, those using traditional methods and folkloric methods were recoded as '0' [31, 32].

\section{Independent variables}

Fifteen independent variables, grouped into individual and contextual level factors were considered in this study. These variables were not determined a priori; but were selected based on their theoretical relevance and practical significance with usage of modern contraceptives [26, 33-35].

\section{Individual level factors}

The individual level factors were age, marital status, religion, employment status, age at first sex, parity, frequency of reading newspaper/magazine, listening to radio and watching television, desire for more children and ideal number of children. Age was coded as '15-19' 
and '20-24'. Marrital status was recoded into 'never married', 'married', 'cohabiting' and 'widowed/divorced/ separated'. Religion was recoded as 'Christianity', 'Islam' and 'other'. 'Working' and 'not working' were the categories for employment status. Age at first sex was recoded as 'less than 15 years' '15-19 years' and '20-24 years'. Parity was recoded as 'zero birth', 'one birth', 'two births', 'three births', and four or more births'. Frequency of reading newspaper/magazine, listening to radio and watching television were each coded as 'not at all' 'less than once a week' and 'at least once a week'. 'Desire for more children and idela number of children were derived from the questions, "do you desire to have a/another child?" and "what is the ideal number of children you want to have?". For this study, desire for more children was coded as "have another", "undecided" and "no more". Ideal number of children was also coded as " 0 3 ", "4-5" and 6+".

\section{Community level factors}

Residence, community literacy level (proportion of women who can read and write), community socio-economic status (proportion of women in the richest household quintile) and community knowledge level of modern contraceptive (proportion of women with knowledge on modern contraceptives) were considered as contextual level factors. Residence was coded as 'urban' and 'rural'. Community literacy level, community socio-economic status and community knowledge level of modern contraceptives were each coded as 'low', 'middle' and 'high'.

\section{Statistical analyses}

The data were analysed with Stata version 14.2 for windows following a three-step analytical approach. The first approach involved the use of percentages to describe the prevalence of modern contraceptive use among AGYW in SSA. This was followed by the distribution of modern contraceptive use across the individual and contextual level factors. Statistical significance of the association between each of the factors and modern contraceptive use was measured using Pearson's chisquare test of independence $\left[\mathrm{x}^{2}\right]$ at a $p$-value of less than 0.05 (see Table 1). Finally, a two-level multilevel binary logistic regression analysis was carried out to examine the association between modern contraceptive use and the individual and contextual factors. The use of a multilevel binary logistic regression in this study was to cater for the different levels at which sampling was done for the DHS (individual, household and cluster levels). The two-level modelling in this study implies that women were nested within households and households were nested within clusters. Clusters were considered as random effects to cater for the unexplained variability at the contextual level [36]. Only variables that showed statistically significant associations with modern contraceptive utilization at the chi-square test were included in the multilevel binary logistic regression models.

In terms of the modelling, four models, comprising the empty model (model 0), model 1 model 2 and model 3 were fitted. Model 0 showed the variance in modern contraceptive use attributed to the clustering of the primary sampling units (PSUs) without the explanatory variables. Model 1 and model 2 contained the individual and contextual level factors respectively while model 3 contained all the individual and contextual level factors. The Stata command "melogit" was used in fitting these models. Model comparison was done using the log likelihood and Akaike's Information Criterion (AIC) tests. The lowest AIC $(90,917.38)$ and highest log likelihood (-45, 426.69) were used to determine the best fit model (see Table 2). Odds ratio and associated 95\% confidence intervals (CIs) were presented for all the models apart from model 0 (see Table 2). To check for high correlation among the explanatory variables, a test for multicollinearity was carried out using the variance inflation factor (VIF) and the results showed no evidence of high collinearity (Mean VIF $=1.35$, Maximum $\mathrm{VIF}=1.86$, and Minimum VIF = 1.06). Sample weight $(v 005 / 1,000,000)$ and SVY command were used to correct for over and undersampling and the complex survey design and generalizability of the findings respectively. The findings were presented using the Strengthening Reporting of Observational studies in Epidemiology (STROBE) reporting guidelines [37].

\section{Ethical approval}

Ethical clearance were obtained from the Ethics Committee of ORC Macro Inc. as well as Ethics Boards of partner organisations of the various countries such as the Ministries of Health. The DHS follows the standards for ensuring the protection of respondents' privacy. Inner City Fund (ICF) International ensured that the survey complies with the U.S. Department of Health and Human Services regulations for the respect of human subjects. This was a secondary analyses of data and therefore no further approval was required since the data is available in the public domain. Further information about the DHS data usage and ethical standards are available at http://goo.gl/ny8T6X.

\section{Results}

Figure 1 displays the results on the prevalence of modern contraceptive use among AGYW in SSA. It was found that $24.7 \%$ of AGYW in the 29 countries in SSA considered in this study use modern contraception. Lesotho recorded the highest prevalence of modern contraceptive use among AGYW (59.2\%) while Chad had the lowest prevalence of $5.1 \%$. 
Table 2 Distribution of modern contraceptive use across individual and contextual factors of adolescent girls and young women in sub-Saharan Africa

\begin{tabular}{|c|c|c|c|c|}
\hline Variables & Weighted N & Weighted \% & Modern contraceptive use & $x^{2}$ ( $p$-value) \\
\hline \multicolumn{4}{|l|}{ Age } & $365.7(<0.001)$ \\
\hline $15-19$ & 33,197 & 36.4 & 21.1 & \\
\hline $20-24$ & 57,886 & 63.6 & 26.8 & \\
\hline \multicolumn{4}{|l|}{ Marital status } & $476.9(<0.001)$ \\
\hline Never married & 33,359 & 36.6 & 28.5 & \\
\hline Married & 38,564 & 42.3 & 21.3 & \\
\hline Cohabiting & 14,012 & 15.4 & 24.6 & \\
\hline Widowed/divorced/separated & 5148 & 5.7 & 25.7 & \\
\hline \multicolumn{4}{|l|}{ Religion } & $8.2(<0.001)$ \\
\hline Christianity & 60,928 & 66.9 & 29.1 & \\
\hline Islam & 25,992 & 28.5 & 15.0 & \\
\hline Other & 4162 & 4.6 & 20.5 & \\
\hline \multicolumn{4}{|l|}{ Employment status } & $45.3(<0.001)$ \\
\hline Not working & 37,956 & 41.7 & 26.2 & \\
\hline Working & 53,127 & 58.3 & 23.6 & \\
\hline \multicolumn{4}{|l|}{ Age at first sex } & $281.8(<0.001)$ \\
\hline Less than 15 years & 19,252 & 21.1 & 20.1 & \\
\hline $15-19$ years & 65,236 & 71.6 & 25.9 & \\
\hline 20-24 years & 6595 & 7.2 & 26.2 & \\
\hline \multicolumn{4}{|l|}{ Parity } & $371.0(<0.001)$ \\
\hline No birth & 33,799 & 37.1 & 22.3 & \\
\hline One birth & 31,748 & 34.9 & 27.0 & \\
\hline Two births & 16,884 & 18.5 & 27.6 & \\
\hline Three births & 6577 & 7.2 & 21.7 & \\
\hline Four or more births & 2074 & 2.3 & 14.7 & \\
\hline \multicolumn{4}{|c|}{ Frequency of reading newspaper/magazine } & $7.9(<0.001)$ \\
\hline Not at all & 70,291 & 77.2 & 21.4 & \\
\hline Less than once a week & 10,880 & 12.0 & 35.4 & \\
\hline At least once a week & 9912 & 10.9 & 36.5 & \\
\hline \multicolumn{4}{|l|}{ Frequency of listening to radio } & $698.1(<0.001)$ \\
\hline Not at all & 36,24 & 40.1 & 20.5 & \\
\hline Less than once a week & 17,828 & 19.6 & 26.0 & \\
\hline At least once a week & 36,731 & 40.3 & 28.3 & \\
\hline \multicolumn{4}{|l|}{ Frequency of watching television } & $640.2(<0.001)$ \\
\hline Not at all & 48,953 & 53.8 & 21.6 & \\
\hline Less than once a week & 11,640 & 12.8 & 25.9 & \\
\hline At least once a week & 30,490 & 33.5 & 29.3 & \\
\hline \multicolumn{4}{|l|}{ Desire for more children } & $263.2(<0.001)$ \\
\hline Have another & 81,348 & 89.3 & 24.4 & \\
\hline Undecided & 3668 & 4.0 & 20.1 & \\
\hline No more & 6067 & 6.7 & 31.7 & \\
\hline \multicolumn{4}{|l|}{ Ideal number of children } & $12.5(<0.001)$ \\
\hline $0-3$ & 28,448 & 31.2 & 33.7 & \\
\hline
\end{tabular}


Table 2 Distribution of modern contraceptive use across individual and contextual factors of adolescent girls and young women in sub-Saharan Africa (Continued)

\begin{tabular}{clll}
\hline Variables & Weighted $\mathbf{N}$ & Weighted $\%$ & Modern contraceptive use \\
\hline $4-5$ & 41,582 & 45.7 & 25.6 \\
$6+$ & 21,052 & 23.1 & 10.8
\end{tabular}

Place of residence

\begin{tabular}{|c|c|c|c|}
\hline Urban & 37,290 & 40.9 & 30.0 \\
\hline Rural & 53,793 & 59.1 & 21.0 \\
\hline
\end{tabular}

Community literacy level

$\begin{array}{llll}\text { Low } & 29,156 & 32.0 & 18.1 \\ \text { Moderate } & 33,323 & 36.6 & 27.0 \\ \text { High } & 28,603 & 31.4 & 28.8\end{array}$

Community socio-economic status

$\begin{array}{llll}\text { Low } & 50,072 & 55.0 & 19.9 \\ \text { Moderate } & 7563 & 8.3 & 30.7 \\ \text { High } & 33,448 & 36.7 & 30.5\end{array}$

Community knowledge of modern method

$\begin{array}{llll}\text { Low } & 72,827 & 78.0 & 27.1 \\ \text { Moderate } & 16,786 & 18.4 & 15.6 \\ \text { High } & 1470 & 1.6 & 9.5\end{array}$

Source: Demographic and Health Surveys

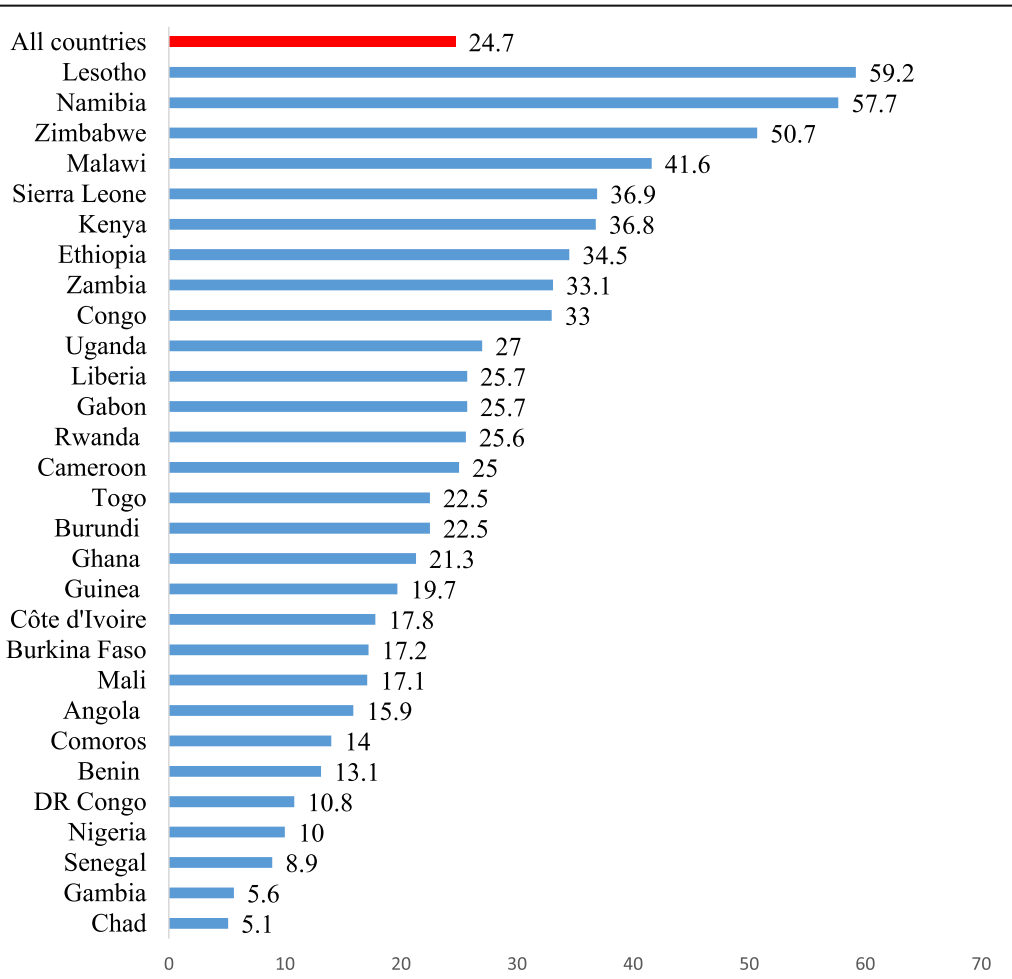

Fig. 1 Prevalence of modern contraceptive usage among adolescent girls and young women in SSA. Source: Demographic and Health Surveys 


\section{Distribution of modern contraceptive use across the individual and contextual level factors}

Table 2 shows results on the distribution of modern contraceptive use across the individual and contextual level factors of AGYW in SSA. The results indicate that the use of modern contraceptives was high among AGYW aged 20-24 (26.8\%), those who had never married (28.5\%), Christians (29.1\%), those who were not working (26.2\%), those who had their first sex between 20 and 24 years (26.2\%), those with two births (27.6\%) and those who read newspaper/magazine, listened to radio or watched television at least once a week. A greater proportion of AGYW also used modern contraceptives if they desired to have no more children (31.7\%), had $0-3$ as their ideal number of children (33.7\%), lived in urban areas (30\%), lived in communities with high literacy (28.8\%), moderate socio-economic status $(30.7 \%)$ and low knowledge of modern methods (27.1\%). The chisquare test results also revealed all the individual and contextual factors had statistically significant associations with modern contraceptive usage.

\section{Association between individual and contextual level factors and modern contraceptive use among AGYW in SSA}

In terms of the individual level factors, the study showed that AGYW aged 15-19 were less likely to use modern contraceptives $[\mathrm{aOR}=0.86, \mathrm{CI}=0.83-0.90]$ compared with those aged 20-24. AGYW who were either married $[\mathrm{aOR}=0.83, \mathrm{CI}=0.79-0.87]$, cohabiting $\quad[\mathrm{aOR}=0.69$, $\mathrm{CI}=0.66-0.73]$, or widowed $/$ divorced $/$ separated $[\mathrm{aOR}=$ $0.77, \mathrm{CI}=0.72-0.83]$ had lower odds of using modern contraceptives, compared with those who had never married. The likelihood of modern contraceptive use was also low among Muslims $[\mathrm{aOR}=0.59, \mathrm{CI}=0.57$ 0.62] and AGYW who belonged to 'other' religions $[\mathrm{aOR}=0.68, \mathrm{CI}=0.62-0.74]$ compared to Christians. AGYW who were working $[\mathrm{aOR}=0.92, \mathrm{CI}=0.89-0.95]$, those who had no child [aOR $=0.44, \mathrm{CI}=0.42-0.47$, those who had no exposure to newspaper/magazine $[\mathrm{aOR}=0.44, \mathrm{CI}=0.63-0.71]$ and radio $[\mathrm{aOR}=0.82, \mathrm{CI}=$ $0.78-0.86]$ had lower odds of using modern contraceptives. The likelihood of modern contraceptive use among AGYW reduced among those who were not decided on their desire for more children $[\mathrm{aOR}=0.72, \mathrm{CI}=0.65$ $0.80]$ and those whose ideal number of children was $6+$ $[\mathrm{aOR}=0.38, \quad \mathrm{CI}=0.35-0.40]$. Conversely, the use of modern contraceptives was high among AGYW whose age at first sex was $15-19$ years $[\mathrm{aOR}=1.20, \mathrm{CI}=1.12$ 1.28] compared to those whose first sex happened between the ages of 20-24. With the contextual factors, the odds of using modern contraceptives was low among AGYW who lived in rural areas $[\mathrm{aOR}=0.89, \mathrm{CI}=0.85-$
0.93], communities with low literacy level $[\mathrm{aOR}=0.73$, $\mathrm{CI}=0.70-0.77]$, low socio-economic status $[\mathrm{aOR}=0.69$, $\mathrm{CI}=0.65-0.73]$ and high knowledge of modern contraceptives $[\mathrm{aOR}=0.33, \mathrm{CI}=0.27-0.41]$ compared to those who lived in urban areas, communities with high literacy level, high socio-economic status and low knowledge on modern contraceptives (see Table 3).

\section{Discussion}

This study assessed the individual and contextual level correlates of modern contraceptive use among AGYW in SSA. It was found that $24.7 \%$ of AGYW in SSA use modern contraceptives. Age, marital status, religion, employment status, parity, exposure to mass media, desire for more children, ideal number of children and age at first sex were identified as individual level predictors of modern contraceptive use among AGYW in SSA. In terms of the contextual level factors, place of residence, community literacy level, community socio-economic status and community knowledge of modern contraceptives had associations with the utilization of modern contraceptives among AGYW in SSA.

In this study, the use of modern contraceptives was low among AGYW in SSA. In line with this finding, Mutumba, Wekesa [27] also found a low prevalence of $17.8 \%$ of modern contraceptive use among young women in LMICs. AGYW in chad had the lowest prevalence of modern contraceptive use. In a recent study on contraceptive use among adolescents and adult women in LMICs, Li, Patton [38] identified Chad as one of the countries with a low contraceptive prevalence. AGYW in Chad are less likely to use modern contraceptives because in Chad, national guidelines authorized only doctors based in hospitals to provide modern contraceptives such as IUDs and implants. Again, few providers in the country have been given the training to provide contraceptive services. This often results in the lack of skills and confidence to deliver these services [39]. The cost of modern contraceptive services has also been considered as a barrier to the use of modern contraceptives, especially among AGYW in Chad [39].

This study showed that AGYW aged 15-19 were less likely to use modern contraceptives compared with those aged 20-24. This finding corroborates the findings obtained in previous studies $[20,21]$. The possible reason for this finding is that AGYW aged 20-24 are assumed to have a better understanding of the consequences of engaging in sexual acts without contraception compared to those aged 15-19 [21]. AGYW aged 15-19 may also have challenges accessing family planning services either because they have no knowledge on where to obtain contraception or cannot afford the services $[40,41]$. Relatedly, this study identified a high usage of modern contraceptives among AGYW who had 
Table 3 Mixed effects results on individual and contextual factors associated with modern contraceptive use among adolescent girls and young women in sub-Saharan Africa

\begin{tabular}{|c|c|c|c|c|}
\hline Variables & $\begin{array}{l}\text { Model } 0 \\
\text { aOR[95\%Cl] }\end{array}$ & $\begin{array}{l}\text { Model } 1 \\
\text { aOR[95\%Cl] }\end{array}$ & $\begin{array}{l}\text { Model } 2 \\
\text { aOR[95\%Cl] }\end{array}$ & $\begin{array}{l}\text { Model } 3 \\
\text { aOR[95\%Cl] }\end{array}$ \\
\hline \multicolumn{5}{|l|}{ Age } \\
\hline $15-19$ & & $0.82^{* * *}(0.79-0.86)$ & & $0.86^{* * *}(0.83-0.90)$ \\
\hline $20-24$ & & 1 & & 1 \\
\hline \multicolumn{5}{|l|}{ Marital status } \\
\hline Not married & & 1 & & 1 \\
\hline Married & & $0.80^{* * *}(0.76-0.83)$ & & $0.83^{* * *}(0.79-0.87)$ \\
\hline Cohabiting & & $0.68^{* * *}(0.65-0.72)$ & & $0.69^{* * *}(0.66-0.73)$ \\
\hline Widowed/separated/divorced & & $0.78^{* * *}(0.72-0.84)$ & & $0.77^{* * *}(0.72-0.83)$ \\
\hline \multicolumn{5}{|l|}{ Religion } \\
\hline Christianity & & 1 & & 1 \\
\hline Islam & & $0.58^{* * *}(0.55-0.60)$ & & $0.59^{* * *}(0.57-0.62)$ \\
\hline Other & & $0.69^{* * * *}(0.63-0.75)$ & & $0.68^{* * *}(0.62-0.74)$ \\
\hline \multicolumn{5}{|l|}{ Employment status } \\
\hline Not working & & 1 & & 1 \\
\hline Working & & $0.89^{* * *}(0.86-0.92)$ & & $0.92^{* * *}(0.89-0.95)$ \\
\hline \multicolumn{5}{|l|}{ Age at first sex } \\
\hline Less than 15 years & & $0.99(0.91-1.06)$ & & $1.03(0.95-1.11)$ \\
\hline 15-19years & & $1.18^{* * *}(1.11-1.26)$ & & $1.20^{* * *}(1.12-1.28)$ \\
\hline $20-24$ years & & 1 & & 1 \\
\hline \multicolumn{5}{|l|}{ Parity } \\
\hline Zero birth & & $0.48^{* * *}(0.45-0.50)$ & & $0.44^{* * *}(0.42-0.47)$ \\
\hline One birth & & $0.78^{* * *}(0.75-0.82)$ & & $0.76^{* * *}(0.72-0.80)$ \\
\hline Two births & & 1 & & 1 \\
\hline Three births & & $0.92^{*}(0.85-0.98)$ & & $0.94(0.87-1.01)$ \\
\hline Four or more births & & $0.85^{* *}(0.75-0.96)$ & & $0.88(0.77-1.00)$ \\
\hline \multicolumn{5}{|c|}{ Frequency of reading newspaper/magazine } \\
\hline Not at all & & $0.65^{* * *}(0.61-1.82)$ & & $0.67^{* * *}(0.63-0.71)$ \\
\hline Less than once a week & & $1.02(0.96-1.08)$ & & $0.98(0.91-1.04)$ \\
\hline At least once a week & & 1 & & 1 \\
\hline \multicolumn{5}{|l|}{ Frequency of listening to radio } \\
\hline Not at all & & $0.80^{* * *}(0.77-0.83)$ & & $0.82^{* * *}(0.78-0.86)$ \\
\hline Less than once a week & & $1.00(0.95-1.04)$ & & $0.99(0.95-1.04)$ \\
\hline At least once a week & & 1 & & 1 \\
\hline \multicolumn{5}{|l|}{ Frequency of watching television } \\
\hline Not at all & & $0.85^{* * *}(0.81-0.88)$ & & $0.97(0.93-1.01)$ \\
\hline Less than once a week & & $0.92^{* *}(0.88 .0 .97)$ & & $1.00(0.95-1.06)$ \\
\hline At least once a week & & 1 & & 1 \\
\hline \multicolumn{5}{|l|}{ Desire for more children } \\
\hline Have another & & $1.10^{* *}(1.03-1.17)$ & & $1.08^{*}(1.01-1.15)$ \\
\hline Undecided & & $0.70^{* * *}(0.63-0.77)$ & & $0.72^{* * *}(0.65-0.80)$ \\
\hline No more & & 1 & & 1 \\
\hline \multicolumn{5}{|l|}{ Ideal number of children } \\
\hline $0-3$ & & 1 & & 1 \\
\hline
\end{tabular}


Table 3 Mixed effects results on individual and contextual factors associated with modern contraceptive use among adolescent girls and young women in sub-Saharan Africa (Continued)

\begin{tabular}{|c|c|c|c|c|}
\hline Variables & $\begin{array}{l}\text { Model } 0 \\
\text { aOR[95\%Cl] }\end{array}$ & $\begin{array}{l}\text { Model } 1 \\
\text { aOR[95\%Cl] }\end{array}$ & $\begin{array}{l}\text { Model } 2 \\
\text { aOR[95\%Cl] }\end{array}$ & $\begin{array}{l}\text { Model } 3 \\
\text { aOR[95\%Cl] }\end{array}$ \\
\hline $4-5$ & & $0.73^{* * *}(0.70-0.75)$ & & $0.78^{* * *}(0.75-0.81)$ \\
\hline $6+$ & & $0.31^{* * *}(0.29-0.32)$ & & $0.38^{* * *}(0.35-0.40)$ \\
\hline \multicolumn{5}{|l|}{ Place of Residence } \\
\hline Urban & & & 1 & 1 \\
\hline Rural & & & $0.83^{* * *}(0.79-0.86)$ & $0.89^{* * *}(0.85-0.93)$ \\
\hline \multicolumn{5}{|l|}{ Community literacy level } \\
\hline Low & & & $0.63^{* * *}(0.60-0.66)$ & $0.73^{* * *}(0.70-0.77)$ \\
\hline Moderate & & & $0.98(0.94-1.02)$ & $0.95^{*}(0.92-0.99)$ \\
\hline High & & & 1 & 1 \\
\hline \multicolumn{5}{|c|}{ Community socio-economic status } \\
\hline Low & & & $0.66^{* * *}(0.63-0.70)$ & $0.69^{* * *}(0.65-0.73)$ \\
\hline Moderate & & & 1 & 1 \\
\hline High & & & $0.96(0.91-1.02)$ & $0.90^{* * *}(0.84-0.95)$ \\
\hline \multicolumn{5}{|c|}{ Community knowledge of modern method } \\
\hline Low & & & 1 & 1 \\
\hline Moderate & & & $0.43^{* * *}(0.40-0.44)$ & $0.53^{* * *}(0.51-0.56)$ \\
\hline High & & & $0.24^{* * *}(0.19-0.29)$ & $0.33^{* * *}(0.27-0.41)$ \\
\hline \multicolumn{5}{|l|}{ Random effect result } \\
\hline PSU variance $(95 \% \mathrm{Cl})$ & $0.03(0.02-0.04)$ & $0.02(0.01-0.03)$ & $0.03(0.01-0.04)$ & $0.02(0.01-0.03)$ \\
\hline ICC & 0.008 & 0.006 & 0.007 & 0.006 \\
\hline LR Test & $x^{2}=91.46, p<0.001$ & $x 2=47.41, p<0.001$ & $x 2=68.69, p<0.001$ & $x^{2}=45.92, p<0.001$ \\
\hline Wald chi-square & Reference & $6019.62^{* * *}$ & $3323.50^{* * *}$ & $7015.95^{* * *}$ \\
\hline \multicolumn{5}{|l|}{ Model fitness } \\
\hline Log-likelihood & $-49,667.17$ & $-46,122.51$ & $-47,848.36$ & $-45,426.69$ \\
\hline AIC & $99,338.16$ & $92,295.02$ & $95,714.72$ & $90,917.38$ \\
\hline $\mathrm{N}$ & 91,083 & 91,083 & 91,083 & 91,083 \\
\hline
\end{tabular}

Source: Demographic and Health Surveys

1 Reference category, PSU Primary Sampling Unit, ICC Intra-Class Correlation, LR Test Likelihood ratio Test, AIC Akaike's Information Criterion ${ }^{*} p<0.05,{ }^{* *} p<0.01,{ }^{* * *} p<0.001$

their first sex between the ages of 15-19 and those who had never married. The possible reason for these findings is the link between marital status and modern contraceptive use. Studies have explained that AGYW who have never married are more likely to use modern contraceptives to prevent unintended pregnancies [42, 43] while those who are married are confronted with pressure to have a child soon after marriage which expose them to pregnancy even if they had the intention to delay pregnancy [44]. This is true, especially among those whose age at first sex occurs below 20 years as this is more likely to occur outside wedlock $[45,46]$. The findings are also in line with the theoretical underpinning of the Health Belief Model which explains that AGYW who consider themselves as being at risk of unintended pregnancies and STIs may be more likely to use modern contraceptives compared to those who consider themselves not to be at risk [18].

Muslim AGYW and those who belonged to 'other' religions were less likely to use modern contraceptives compared to Christians. This finding is supported by the findings of other studies [47-49]. This may be attributed to differences in religious teachings regarding the use of contraceptives for fertility control [47]. As found in this study, in religions where high parity is desired and fertility preferences are high, there is low likelihood of the use of modern contraceptives. Specifically for Muslim AGYW, a study by Abdi, Okal [50] in two Muslim communities in Kenya showed that Muslim women tend to have high desire for more children due to the belief that children are a blessing from God. Thus, to receive more of the blessings God has in stock for them in the form 
of children, they will be less likely to use modern contraceptives. This finding could be true especially when previous studies have found high prevalence of child marriage among Muslims and other religious adherents compared to Christians [51, 52]. Despite this finding, there is the need for future qualitative research to explore further on why Christian AGYW are more likely to use modern contraceptives compared to Muslims and AGYW who belong to 'other' religion. In the meantime, there is the need to formulate and disseminate particular culturally appropriate messages targeting sexually active AGYW on the importance of modern contraceptive use in line with their religious beliefs and practices.

In this study, AGYW who lived in socio-economically disadvantaged communities (rural areas, communities with low literacy level and low socio-economic status) were less likely to use modern contraceptives compared to those who lived in socio-economically advantaged communities. This finding is in agreement with the findings of previous studies $[53,54]$. This finding could be attributed to economic empowerment that gives AGYW in socioeconomically advantaged communities more economic power to access modern contraceptives as the barriers in terms of cost are catered for [55-57]. Theoretically, AGYW who are in socio-economically disadvantaged communities might not have the perceived behavioural control to utilise modern contraceptives when they are financially not viable to purchase these modern contraceptives [58]. Despite the role of advantaged socio-economic status on the use of modern contraceptives, AGYW who were working had lower odds of using modern contraceptives compared to those who were not working. The possible reason for this finding could be that the majority of non-working AGYW may be in school and hence may consider the use of contraceptives as a means of preventing pregnancy and delaying fertility. Similar findings were obtained in Nigeria [36] and Ghana [59].

Non-exposure to media (radio and newspaper/magazine) decreased the odds of modern contraceptive use among AGYW in this study. This finding relates to the findings of studies in other SSA countries like Ghana [23], Mali [60], Nigeria [61, 62] and Senegal [63]. It can be affirmed that access to mass media is likely to lead to exposure to family planning messages which can bring about change in AGYW's negative attitude with respect to contraception [61]. Relatedly, Sharma, Ghimire [64] also observed that women who are exposed to family planning messages through health facilities, radio, and television have a greater likelihood to use modern contraceptives in Nepal. However, AGYW who lived in communities with high knowledge on modern contraceptives were less likely to use modern contraceptives. Further research is needed to understand this counterintuitive finding.

\section{Strengths and limitations}

The use of nationally representative and current datasets in this study and the focus on AGYW in SSA is a major strength in this study. Again, the large sample size, the use of rigorous statistical analysis that considers both individual and contextual level factors associated with modern contraceptive use and the use of validated instruments in the DHS strengthen the validity of findings from the dataset. However, the use of cross-sectional design in the surveys makes it impossible to establish causality with respect to the findings. There is also the possibility of response bias since the issue on contraceptive use may lead to provision of social desirable responses and AGYW may also find it challenging to recall previous events on the use of modern contraception. The differences in survey years can also affect the comparability of the findings since modernization may play a role in the prevalence of modern contraceptives use in more current surveys compared to older ones.

\section{Conclusion}

Modern contraceptive use among the AGYW in SSA remains low and this can result in high rates of unwanted or mistimed pregnancies and risk of contracting STIs including HIV/AIDS. Therefore, Governments in the various countries considered in this study through their policy makers should put in measures that will halt barriers to access and use of modern contraceptives whilst intensifying mass education on modern contraceptive methods. This education should be more centered on AGYW who are in socio-economically disadvantaged communities, those who are not married, Muslims, those with high parity and high fertility preferences and those who are working. Further studies is essential to unearth the reasons why AGYW who live in communities with high knowledge on modern contraceptives are less likely to use modern contraceptives.

\section{Abbreviations \\ AGYW: Adolescent girls and young women; AIC: Akaike's Information Criterion; aOR: Adjusted odds ratios; DHS: Demographic and Health Survey; ICC: Intra-Class Correlation; LR Test: Likelihood ratio Test; PSU: Primary Sampling Unit; SRH: Sexual and reproductive health; SSA: Sub-Saharan Africa}

\section{Acknowledgements}

The author thanks the MEASURE DHS project for their support and for free access to the original data.

\section{Author's contributions}

$\mathrm{BOA}$ contributed to the study design and conceptualization. BOA reviewed the literature and performed the analysis. BOA provided technical support and critically reviewed the manuscript for its intellectual content. BOA had final responsibility to submit for publication. The author read and amended drafts of the paper and approved the final version.

Funding

There was no funding for this study. 


\section{Availability of data and materials}

Data for this study were sourced from Demographic and Health surveys (DHS) and available here: http://dhsprogram.com/data/available-datasets.cfm.

\section{Ethics approval and consent to participate}

Ethics approval was not required for this study since the data is secondary and is available in the public domain. More details regarding DHS data and ethical standards are available at: http://goo.gl/ny8T6X.

\section{Consent for publication}

No consent to publish was needed for this study as the author did not use any details, images or videos related to individual participants. In addition, data used are available in the public domain.

\section{Competing interests}

The author declares no competing interest.

\section{Received: 4 September 2020 Accepted: 10 November 2020} Published online: 19 November 2020

\section{References}

1. Morris JL, Rushwan H. Adolescent sexual and reproductive health: the global challenges. Int J Gynecol Obstet. 2015;131:S40-S2.

2. Patton GC, Sawyer SM, Santelli JS, Ross DA, Afifi R, Allen NB, et al. Our future: a lancet commission on adolescent health and wellbeing. Lancet. 2016;387(10036):2423-78.

3. Adolescent pregnancy. Fact sheet No. 364 [Internet]. 2014 [cited Accessed July 4, 2020]. Available from: http://www.who.int/mediacentre/factsheets/fs364/en/.

4. Ameyaw EK, Budu E, Sambah F, Baatiema L, Appiah F, Seidu A-A, et al. Prevalence and determinants of unintended pregnancy in sub-Saharan Africa: a multicountry analysis of demographic and health surveys. PLoS One. 2019;14(8).

5. Geda YF. Determinants of teenage pregnancy in Ethiopia: a case-control study, 2019. Curr Med Issues. 2019;17(4):112.

6. Fertility among very young adolescents. [Internet]. Population Division, United Nations Department of Economic and Social Affairs. 2019.

7. United Nations. Sustainable development goals. New York: United Nations; 2015.

8. Darroch JE. Trends in contraceptive use. Contraception. 2013;87(3):259-63.

9. Darroch JE, Singh S. Trends in contraceptive need and use in developing countries in 2003, 2008, and 2012: an analysis of national surveys. Lancet. 2013;381(9879):1756-62.

10. Tsui AO, Brown W, Li Q. Contraceptive practice in sub-Saharan Africa. Popul Dev Rev. 2017:43(Suppl Suppl 1):166.

11. Behrman JA, Wright KQ, Grant MJ, Soler-Hampejsek E. Trends in modern contraceptive use among young adult women in sub-Saharan Africa 1990 to 2014. Stud Fam Plan. 2018;49(4):319-44.

12. Radovich E, Dennis ML, Wong KLM, Ali M, Lynch CA, Cleland J, et al. Who meets the contraceptive needs of young women in sub-Saharan Africa? J Adolesc Health. 2018;62(3):273-80.

13. Singh S, Darroch JE. Adding it up: costs and benefits of contraceptive services. New York: Guttmacher Institute and UNFPA; 2012. p. 1269-86.

14. Darroch JE, Sedgh G, Ball H. Contraceptive technologies: responding to women's needs. New York: Guttmacher Institute. 2011;201(1).

15. Ochako R, Mbondo M, Aloo S, Kaimenyi S, Thompson R, Temmerman M, et al. Barriers to modern contraceptive methods uptake among young women in Kenya: a qualitative study. BMC Public Health. 2015;15(1):118.

16. Durowade KA, Omokanye LO, Elegbede OE, Adetokunbo S, Olomofe CO, Ajiboye AD, et al. Barriers to contraceptive uptake among women of reproductive age in a semi-Urban Community of Ekiti state, Southwest Nigeria. Ethiop J Health Sci. 2017;27(2):121-8.

17. Makola L, Mlangeni L, Mabaso M, Chibi B, Sokhela Z, Silimfe Z, et al. Predictors of contraceptive use among adolescent girls and young women (AGYW) aged 15 to 24 years in South Africa: results from the 2012 national population-based household survey. BMC Womens Health. 2019;19(1):158.

18. Rosenthal DA, Hall C, Moore SM. AIDS, adolescents, and sexual risk taking: a test of the health belief model. Aust Psychol. 1992;27(3):166-71.

19. Azfredrick EC. Using Anderson's model of health service utilization to examine use of services by adolescent girls in South-Eastern Nigeria. Int J Adolesc Youth. 2016;21(4):523-9.

20. Casey SE, Gallagher MC, Kakesa J, Kalyanpur A, Muselemu J-B, Rafanoharana RV, et al. Contraceptive use among adolescent and young women in North and South Kivu, Democratic Republic of the Congo: a cross-sectional population-based survey. PLoS Med. 2020;17(3):e1003086.

21. Mandiwa C, Namondwe B, Makwinja A, Zamawe C. Factors associated with contraceptive use among young women in Malawi: analysis of the 2015-16 Malawi demographic and health survey data. Contracept Reprod Med. 2018;3(1):1-8.

22. Nsanya MK, Atchison CJ, Bottomley C, Doyle AM, Kapiga SH. Modern contraceptive use among sexually active women aged 15-19 years in North-Western Tanzania: results from the adolescent 360 (A360) baseline survey. BMJ Open. 2019;9(8):e030485

23. Appiah F, Seidu A-A, Ahinkorah BO, Baatiema L, Ameyaw EK. Trends and determinants of contraceptive use among female adolescents in Ghana: analysis of 2003-2014 demographic and health surveys. SSM-Population Health. 2020;10:100554.

24. Abiye AA, Fekede B, Jemberie AM, Molla BA, Tolla BK, Tefera BS, et al. Modern contraceptive use and associated factors among reproductive age group women in three Peri-Urban Communities in Central Ethiopia. J Drug Deliv Ther. 2019,9(6-s):93-102.

25. Ajayi Al, Adeniyi OV, Akpan W. Use of traditional and modern contraceptives among childbearing women: findings from a mixed methods study in two southwestern Nigerian states. BMC Public Health. 2018;18(1):604.

26. Debebe S, Limenih MA, Biadgo B. Modern contraceptive methods utilization and associated factors among reproductive aged women in rural Dembia District, Northwest Ethiopia: community based cross-sectional study. Int J Reprod BioMed. 2017;15(6):367.

27. Mutumba M, Wekesa E, Stephenson R. Community influences on modern contraceptive use among young women in low and middle-income countries: a cross-sectional multi-country analysis. BMC Public Health. 2018;18(1):430.

28. Fabic MS, Choi Y, Bird S. A systematic review of demographic and health surveys: data availability and utilization for research. Bull World Health Organ. 2012;90:604-12.

29. Corsi DJ, Neuman M, Finlay JE, Subramanian SV. Demographic and health surveys: a profile. Int J Epidemiol. 2012;41(6):1602-13.

30. Ahinkorah BO, Hagan JEJ, Seidu A-A, Sambah F, Adoboi F, Schack T. Female adolescents' reproductive health decisionmaking capacity and contraceptive use in subSaharan Africa: what does the future hold? PLoS One. 2020;15(7):1-20.

31. Namasivayam A, Lovell $S$, Namutamba S, Schluter PJ. Predictors of modern contraceptive use among women and men in Uganda: a population-level analysis. BMJ Open. 2020;10(2):e034675.

32. Yussuf MH, Elewonibi BR, Rwabilimbo MM, Mboya IB, Mahande MJ. Trends and predictors of changes in modern contraceptive use among women aged 15-49 years in Tanzania from 2004-2016: evidence from Tanzania demographic and health surveys. PLoS One. 2020;15(6):e0234980.

33. Aviisah PA, Dery S, Atsu BK, Yawson A, Alotaibi RM, Rezk HR, et al. Modern contraceptive use among women of reproductive age in Ghana: analysis of the 20032014 Ghana demographic and health surveys. BMC Womens Health. 2018;18(1):141.

34. Lasong J, Zhang Y, Gebremedhin SA, Opoku S, Abaidoo CS, Mkandawire T, et al. Determinants of modem contraceptive use among married women of reproductive age: a cross-sectional study in rural Zambia. BMJ Open. 2020;10(3):e030980.

35. Ejembi CL, Dahiru T, Aliyu AA. DHS working papers; 2015.

36. Solanke BL, Oyinlola FF, Oyeleye OJ, llesanmi BB. Maternal and community factors associated with unmet contraceptive need among childbearing women in Northern Nigeria. Contracept Reprod Med. 2019;4(1):11.

37. Von Elm E, Altman DG, Egger M, Pocock SJ, Gøtzsche PC, Vandenbroucke $J P$, et al. The strengthening the reporting of observational studies in epidemiology (STROBE) statement: guidelines for reporting observational studies. Int J Surg. 2014;12(12):1495-9.

38. Li Z, Patton G, Sabet F, Zhou Z, Subramanian SV, Lu C. Contraceptive use in adolescent girls and adult women in low-and middle-income countries. JAMA Netw Open. 2020;3(2):e1921437-e.

39. Rattan J, Noznesky E, Curry DW, Galavotti C, Hwang S, Rodriguez M. Rapid contraceptive uptake and changing method mix with high use of long-acting reversible contraceptives in crisis-affected populations in Chad and the Democratic Republic of the Congo. Glob Health Sci Pract. 2016;4(Supplement 2):S5-S20.

40. Binu W, Marama T, Gerbaba M, Sinaga M. Sexual and reproductive health services utilization and associated factors among secondary school students in Nekemte town, Ethiopia. Reprod Health. 2018;15(1):64.

41. Tamang L, Raynes-Greenow C, McGeechan K, Black K. Factors associated with contraceptive use among sexually active Nepalese youths in the Kathmandu Valley. Contracept Reprod Med. 2017;2(1):13.

42. Grindlay K, Dako-Gyeke P, Ngo TD, Eva G, Gobah L, Reiger ST, et al. Contraceptive use and unintended pregnancy among young women and men in Accra, Ghana. PLoS One. 2018;13(8):e0201663.

43. Ahinkorah BO, Seidu A-A, Appiah F, Baatiema L, Sambah F, Budu E, et al. What has reproductive health decision-making capacity got to do with 
unintended pregnancy? Evidence from the 2014 Ghana demographic and health survey. PLoS One. 2019;14(10):e0223389.

44. UNFPA. Girlhood, not motherhood: preventing adolescent pregnancy. In: Fund UNP, editor. New York 2015.

45. Cremin I, Mushati P, Hallett T, Mupambireyi Z, Nyamukapa C, Garnett GP, et al. Measuring trends in age at first sex and age at marriage in Manicaland, Zimbabwe. Sex Transm Infect. 2009;85(Suppl 1):i34-40.

46. Żaba B, Isingo R, Wringe A, Marston M, Slaymaker E, Urassa M. Influence of timing of sexual debut and first marriage on sexual behaviour in later life: findings from four survey rounds in the Kisesa cohort in northern Tanzania. Sex Transm Infect. 2009;85(Suppl 1):i20-i6.

47. Obasohan PE. Religion, ethnicity and contraceptive use among reproductive age women in Nigeria. Int J MCH AIDS. 2015;3(1):63.

48. Adedini SA, Babalola S, Ibeawuchi C, Omotoso O, Akiode A, Odeku M. Role of religious leaders in promoting contraceptive use in Nigeria: evidence from the Nigerian urban reproductive health initiative. Glob Health Sci Pract. 2018;6(3):500-14.

49. Tigabu S, Demelew T, Seid A, Sime B, Manyazewal T. Socioeconomic and religious differentials in contraceptive uptake in western Ethiopia: a mixedmethods phenomenological study. BMC Womens Health. 2018;18(1):1-10.

50. Abdi B, Okal J, Serour G, Temmerman M. "Children are a blessing from god"-a qualitative study exploring the socio-cultural factors influencing contraceptive use in two Muslim communities in Kenya. Reprod Health. 2020;17:1-11.

51. Yaya S, Odusina EK, Bishwajit G. Prevalence of child marriage and its impact on fertility outcomes in 34 sub-Saharan African countries. BMC Int Health Hum Rights. 2019;19(1):33.

52. Odusina EK, Bishwajit G, Yaya S. Prevalence of child marriage and its impact on fertility outcomes in 34 sub-Saharan African countries. J Adolesc Health. 2013:52:552-8.

53. Adebowale SA, Adedini SA, Ibisomi LD, Palamuleni ME. Differential effect of wealth quintile on modern contraceptive use and fertility: evidence from Malawian women. BMC Womens Health. 2014;14(1):40.

54. Rutaremwa G, Kabagenyi A, Wandera SO, Jhamba T, Akiror E, Nviiri HL. Predictors of modern contraceptive use during the postpartum period among women in Uganda: a population-based cross sectional study. BMC Public Health. 2015;15(1):262.

55. Aremu O. The influence of socioeconomic status on women's preferences for modern contraceptive providers in Nigeria: a multilevel choice modeling. Patient Preference Adherence. 2013;7:1213.

56. Abekah-Nkrumah G, Abor PA. Socioeconomic determinants of use of reproductive health services in Ghana. Heal Econ Rev. 2016;6(1):9.

57. Lamidi EO. State variations in women's socioeconomic status and use of modern contraceptives in Nigeria. PLoS One. 2015;10(8):e0135172.

58. Ajzen I. The theory of planned behavior. Organ Behav Hum Decis Process. 1991;50(2):179-211.

59. Guure C, Maya ET, Dery S, Vrom B-C, Alotaibi RM, Rezk HR, et al. Factors influencing unmet need for family planning among Ghanaian married/ union women: a multinomial mixed effects logistic regression modelling approach. Arch Public Health. 2019;77(1):11.

60. Zamawe COF, Banda M, Dube AN. The impact of a community driven mass media campaign on the utilisation of maternal health care services in rural Malawi. BMC Pregnancy Childbirth. 2016;16(1):21.

61. Ajaero CK, Odimegwu C, Ajaero ID, Nwachukwu CA. Access to mass media messages, and use of family planning in Nigeria: a spatio-demographic analysis from the 2013 DHS. BMC Public Health. 2016;16(1):427.

62. Bajoga UA, Atagame KL, Okigbo CC. Media influence on sexual activity and contraceptive use: a cross sectional survey among young women in urban Nigeria. Afr J Reprod Health. 2015;19(3):100-10.

63. Jacobs J, Marino M, Edelman A, Jensen J, Darney B. Mass media exposure and modern contraceptive use among married West African adolescents. Eur J Contracept Reprod Health Care. 2017;22(6):439-49.

64. Sharma SK, Ghimire DR, Pratap N. Ethnic differentials of the impact of family planning program on contraceptive use in Nepal. Demogr Res. 2011;25: 837-68

\section{Publisher's Note}

Springer Nature remains neutral with regard to jurisdictional claims in published maps and institutional affiliations.

\section{Ready to submit your research? Choose BMC and benefit from}

- fast, convenient online submission

- thorough peer review by experienced researchers in your field

- rapid publication on acceptance

- support for research data, including large and complex data types

- gold Open Access which fosters wider collaboration and increased citations

- maximum visibility for your research: over $100 \mathrm{M}$ website views per year

At BMC, research is always in progress.

Learn more biomedcentral.com/submissions 